http://jmscr.igmpublication.org/home/ ISSN (e)-2347-176x ISSN (p) 2455-0450

crossref DOI: https://dx.doi.org/10.18535/jmscr/v7i11.43

\author{
Dournal Of Medical Science And Clinical Research

\title{
Hepatocellular Carcinoma with Bi-atrial invasion
}

Authors

\section{Uthaya Sankar M.K ${ }^{1}$, Sibi Chakravarthy.C ${ }^{2}$, Naveen Sathish. $\mathbf{V}^{3}$}

${ }^{1}$ Professor, ${ }^{2,3}$ Post Graduate Residents, Department of General Medicine, Sri Manakula Vinayagar Medical College and Hospital, Puducherry-605107, India

\begin{abstract}
Hepatocellular carcinoma (HCC) is the most common primary tumor of the liver. The Right heart is affected in up to $2 \%$ of metastatic HCC cases. However this was the first case of HCC to be reported with bi-atrial involvement. CECT showed Multifocal HCC in right lobe of liver with tumour thrombus extending along right portal vein, right hepatic vein into IVC and right atrium and extending across the atrial septum into left atrium via sinus venosus ASD. Intracardiac involvement has got very poor prognosis.
\end{abstract}

\section{Introduction}

Hepatocellular carcinoma (HCC) is the fifth most common cancer in the world and the third most common cause of cancer death ${ }^{1}$. It is the most common primary tumour of the liver. Although HCC usually metastasizes to regional lymph nodes, lung, or bones, it can also invade major local blood vessels and rarely the heart. Metastasis to heart can occur via blood stream or direct invasion of $\mathrm{IVC}^{2}$. For such metastatic disease only chemotherapy or supportive measures alone can be tried.

\section{Case report}

A 60 Year old male who was a chronic alcoholic presented with swelling of both legs followed by abdomen distension with of yellowish discolouration of urine and eyes which was for a duration of 14 days. He was a chronic alcoholic and smoker for 30 years. Similar complaints were present one year back. On general examination patient was malnourished with icterus and bilateral pitting pedal edema. Abdomen examination showed dilated veins over abdomen and back with flow below upwards, tender hepatomegaly and fluid thrill. Blood investigations revealed deranged LFT and Hepatitis B positive. Ascitic fluid analysis revealed a high serum-ascitis albumin gradient (SAAG) and low protein and cytopathology study showed atypical cells. USG abdomen showed multiple ill-defined hyperechoic lesions in liver with coarse echotexture. Echocardiogram revealed right atrial thrombus with sinus venosus ASD.

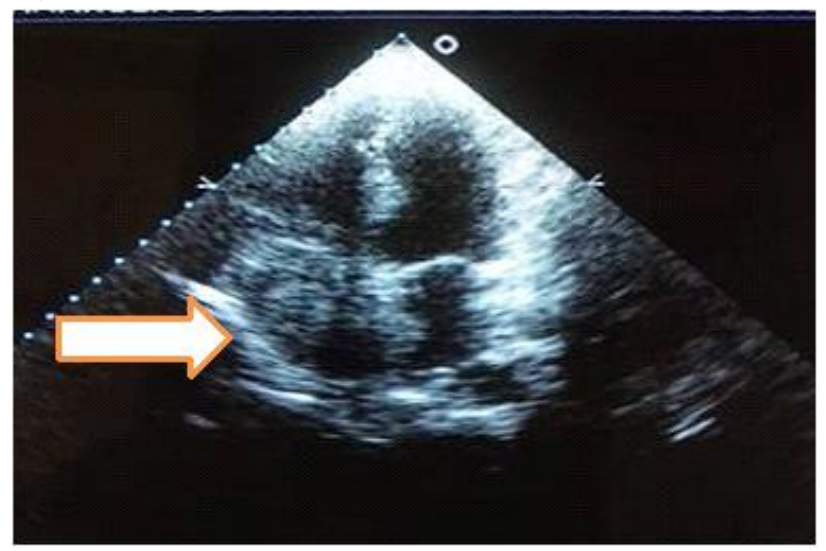

Fig 1: 2D Echocardiogram showing hyperechoic thrombus in both right and left atrium. 
CECT showed Multifocal HCC in right lobe of liver with tumour thrombus extending along right portal vein, right hepatic vein into IVC and right atrium and across the atrial septum into left atrium via sinus venosus ASD. His serum Alpha feto protein was elevated. Patient was staged into stage $\mathrm{C}$ according to BCLC staging system and started on chemotherapy Sorafenib.

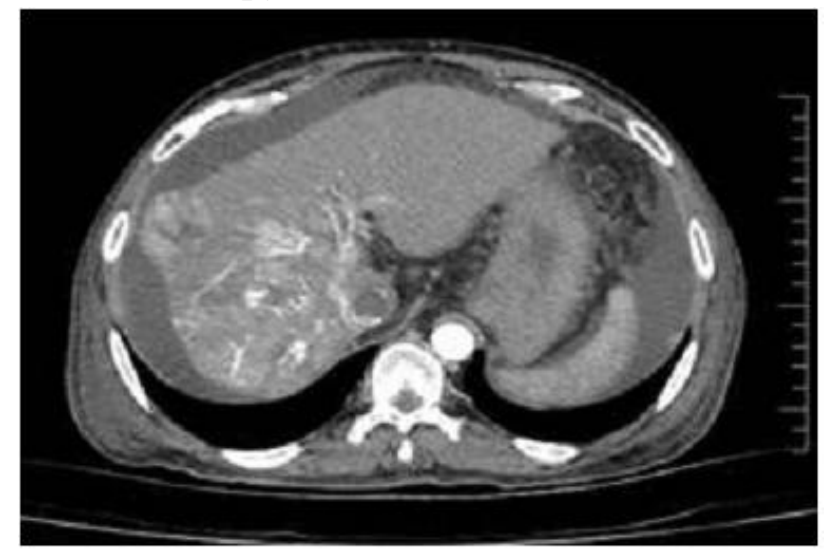

Fig 2: Triphasic CT showing arterial enhancement of liver lesions.

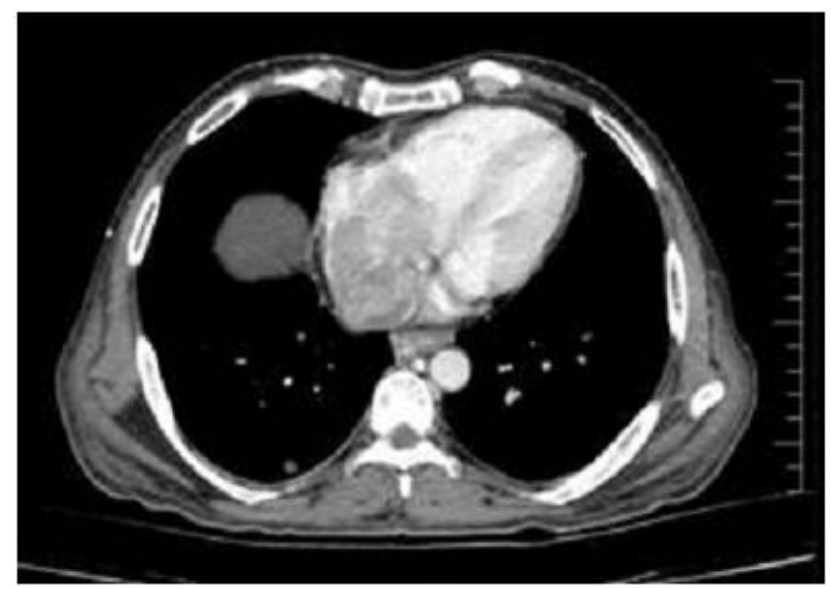

Fig 3: CECT thorax showing tumour thrombus in both the atrium.

\section{Discussion}

The Right heart is affected in up to $2 \%$ of metastatic HCC cases ${ }^{2}$. However this is the first case to be reported with bi-atrial involvement. Intracardiac involvement is extremely rare and has got a very poor prognosis. Metastasis to right atrium can occur via the blood stream or direct invasion of IVC. Median survival range is 1 to 4 months ${ }^{3}$. In this case the tumour thrombus metastasised to the left atrium also via the atrial septal defect.

\section{Conclusion}

This is the first case of hepatocellular carcinoma with tumour extending into both the atrium. The prognosis of such patient is very poor.

\section{References}

1. Kasper DL, Hauser SL, Jameson JL, Fauci AS, Longo DL, Loscalzo J. Harrison's principle of internal medicine twentieth edition New York: The McGraw-Hill Companies;2018.p579.

2. Chang JY, Ka WS, Chao TY, Chuang TR, Chen LT. Hepatocellular carcinoma with intra-atrial tumour thrombi. A report of three cases responsive to thalidomide treatment and literature review. Oncology 2004;67(3-4):320-6.

3. Luo X, Zhang B, Dong S, Zhang B, Chen $X$. Hepatocellular carcinoma with tumour thrombus occupying the right atrium and portal vein: A case report and literature review. Medicine (Baltimore) 2015; 94:e1049. 